\title{
ULTRASTRUCTURAL STUDIES ON STOMATA DEVELOPMENT IN INTERNODES OF AVENA SATIVA ${ }^{1}$
}

\author{
P. B. Kaufman, L. B. Petering, C. S. Yocum, and D. Baic \\ Departments of Botany and Zoology, University of Michigan, Ann Arbor
}

$\begin{array}{llllllllllllllll}\text { A } & \text { B } & \mathbf{S} & \mathbf{T} & \mathbf{R} & \mathbf{A} & \mathbf{C} & \mathbf{T}\end{array}$

\begin{abstract}
A study of stomata development in internodes fixed with glutaraldehyde and osmium tetroxide revealed the following features: (1) young subsidiary and guard cells have proplastids, but in the mature stomatal apparatus only guard cells have starch-containing plastids; (2) cytoplasmic continuities found in the developing stomatal apparatus included (a) plasmodesmata between young guard and subsidiary cells and (b) pores at each end of the guard cells in the wall common to these two cells (the pores are found in immature as well as mature stomata); (3) a locus of microtubules was found just inside the plasmalemma of the wall common to the two guard cells. These microtubules are generally parallel to the radial axis of this wall. They are concentrated at the site where localized wall thickening and aperture formation occur. After wall thickening begins around the developing aperture, microtubules are found running primarily in a plane perpendicular to the wall thickening. The possible functional significance of these microtubules and the cytoplasmic continuities in the stomatal apparatus is discussed.
\end{abstract}

LIGHT MICROSCOPY has yielded considerable information on development of stomata in grasses (Campbell, 1881; Porterfield, 1937; Flint and Moreland, 1946; Kaufman, 1959; Stebbins and Shah, 1960; Bonnett, 1961; Stebbins and Khush, 1961; Ariyanayagam and Stebbins, 1962; Kaufman and Cassell, 1963; Kaufman, Petering, and Adams, 1969). Less is known at the ultrastructural level. Pickett-Heaps and Northcote (1966) and Burgess and Northcote (1967) have shown "preprophase" microtubule bands early in subsidiary cell and guard cell formation. These workers suggest that these bands, coupled with nuclear migration in long cells, denote that a particular short cell in the protoderm will become a stoma mother cell. Others (Brown and Johnson, 1962; Miroslavov, 1966; Pickett-Heaps, 1967a) have clearly demonstrated that pores occur in the common wall between guard cells at the ends of these cells in mature stomata. The kinds of organelles that occur in mature guard and subsidiary cells have also been described (Setterfield, 1957; Brown and Johnson, 1962; Miroslavov, 1966), but here considerable controversy exists regarding the occurrence of plasmodesmata and plastids in both of these types of cells (Ketellapper, 1963). Furthermore, we do not have complete details on the formation of the pores between

${ }^{1}$ Received for publication 14 April 1969.

The authors thank Dr. Robert Lowry for helpful suggestions and use of the RCA EMU 3-G electron microscope in the Department of Botany, University of Michigan, Drs. Hilton Mollenhauer and Horoshi Ikuma for constructive comments on the manuscript, and $\mathrm{Mr}$. Louis Martonyi for his photographic work.

This research was supported under auspices of National Science Foundation grant GB-2688 and H. H. Rackham grant 793 (University of Michigan). the guard cells or on the process of wall thickening around the developing aperture. Few have speculated on the possible roles that these pores or the plasmodesmata play in the functioning of the stomatal apparatus. In this paper, we present new data on these events in stomata development and discuss the possible functional significance of the cytoplasmic continuities in the stomatal apparatus.

MATERIALS AND METHODS-Shoots of Avena sativa 'Victory' were obtained from 45-50-dayold plants grown in the greenhouse with a mean day temperature of $26 \mathrm{C}$ and a mean night temperature of $22 \mathrm{C}$. Internodes 1-2 cm long were used for early stages, while older internodes $8-10 \mathrm{~cm}$ long were used for late stages.

In the light microscopy studies epidermal peels were prepared, stained, and photographed as cited in Kaufman et al. (1969). For electron microscopy studies the internodes were cut transversely into 1-mm segments, then cut lengthwise into three strips and fixed. For fixaation we used formaldehyde-glutaraldehyde (Karnovsky, 1965) for $2-5 \mathrm{hr}$, first at $23 \mathrm{C}$, then at 0 to $-4 \mathrm{C}$. The tissue was then post-fixed in $1.33 \% \mathrm{OsO}_{4}$ for $2 \mathrm{hr}$ (Karnovsky, 1965). All tissues were washed in distilled water and dehydrated in an alcohol-acetone series. Tissues were embedded in an araldite-dibutylphthalate mixture (no. 1 of Mollenhauer, 1964). Sections were obtained with a Porter-Blum MT-2 ultramicrotome and were viewed and photographed with the RCA EMU 3-G. The sections were stained and post-stained with $0.5 \%$ uranyl acetate and Reynolds' lead citrate stain, respectively (Reynolds, 1963). 


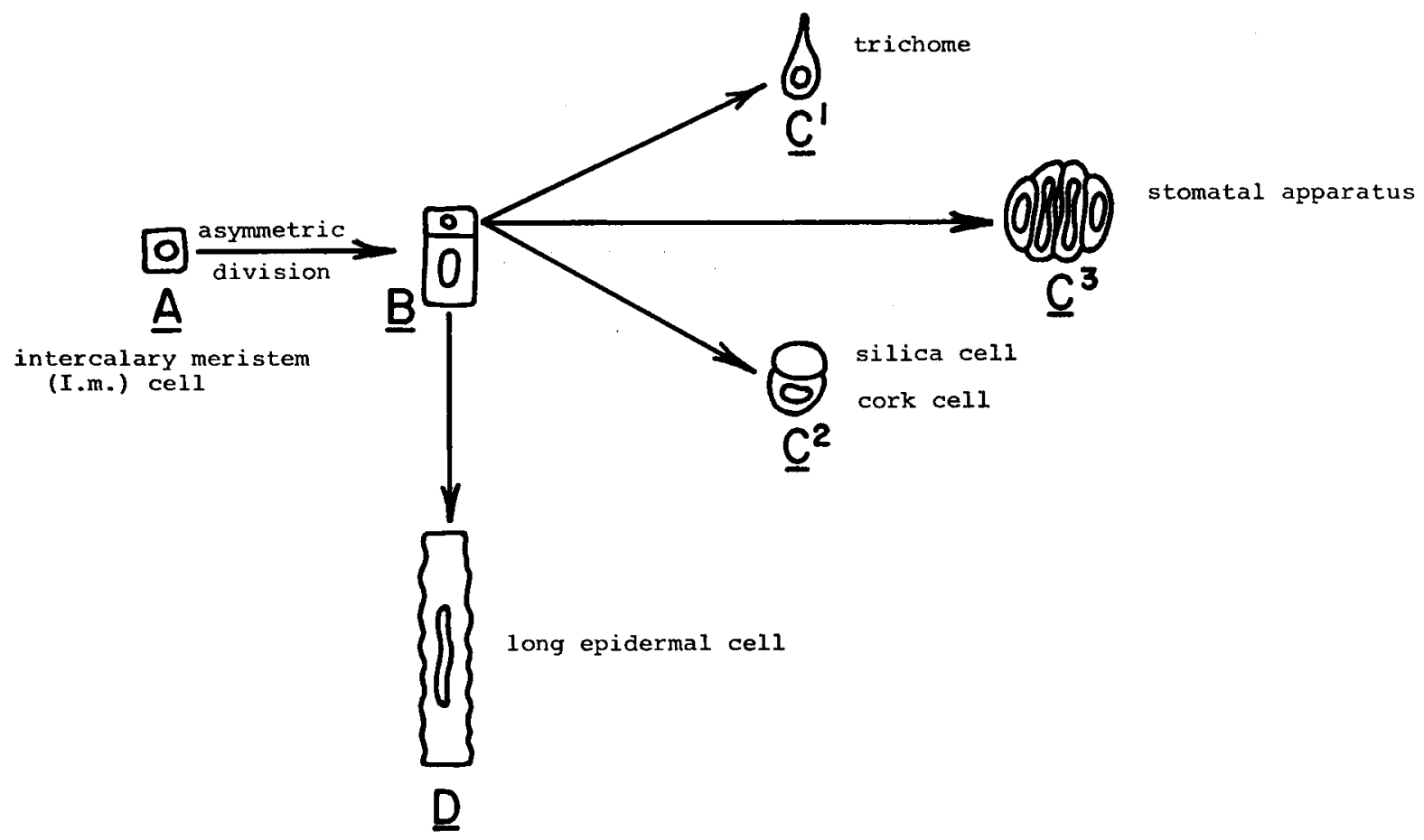

Fig. 1. Diagram indicating pathways of development of epidermal cells as observed in Avena internodes. In pathway from short cell $(B)$ to stomatal apparatus $\left(C^{3}\right)$, only the two center guard cells are derived from the short cell; the flanking subsidiary cells arise from adjacent long cells which are not shown in diagram.

'Victory' oats were obtained from the Swedish Seed Ass., Svalöf, Sweden.

Observatrons-Stomata development (Gramineae)-The first stage of differentiation is an asymmetric division of a protoderm cell just above the base of the internode. The short cell derivative of this division differentiates to form an idioblast; namely, the guard cells of the stomatal apparatus, or a pair of cork and silica cells, or a trichome (Fig. 1).

Stomata characteristically develop in epidermal cell files lying adjacent to a vascular bundle. The sequence of development proceeds in files of alternating long and short epidermal cells above the intercalary meristem (Fig. 2) in the following manner: (a) subsidiary cells are cut off by the long cells flanking the guard cell mother cell (GCMC) on both sides (Fig. 3, 4); (b) the GCMC then divides longitudinally (Fig. 5-8); (c) following this division, the stomatal apparatus matures by localized wall thickening in the vicinity of the aperture and by conspicuous changes in form of the guard and subsidiary cells (Fig. 9, 10).

Ultrastructural development of the stomatal apparatus - In order to provide a direct comparison with the stages of development as seen in the light microscope (Fig. 2-10), the electron micrographs in Fig. 11-17 are presented here. They will also be used subsequently to indicate pores at the ends of the guard cells, plasmodesmata, wall thickening around the developing aperture, and plastids in the guard cells.

The first stage is that of a short cell between two long epidermal cells (cf. Fig. 2, 11). We shall designate this as the singlet stage in stoma development. That the particular cell shown in Fig. 11 will become a stoma is verified by the preprophase band of microtubules which occurs in the long cell adjacent to this short cell and shown in Fig. 12. This band is the same as described by Pickett-Heaps and Northcote (1966) and by Burgess and Northcote (1967).

Fig. 2-10. Light micrographs illustrating the development of the stomatal apparatus in Avena internodal epidermis.Fig. 2. Illustration of short cells which give rise to stomata (arrows).-Fig. 3. Doublet stage of stomatal development.Fig. 4. Triplet stage, base of figure.-Fig. 5-8. Stages in division of GCMC.-Fig. 9. Quartet stage.-Fig. 10. Fully differentiated stomatal apparatus.-All $\times 2,000$. 

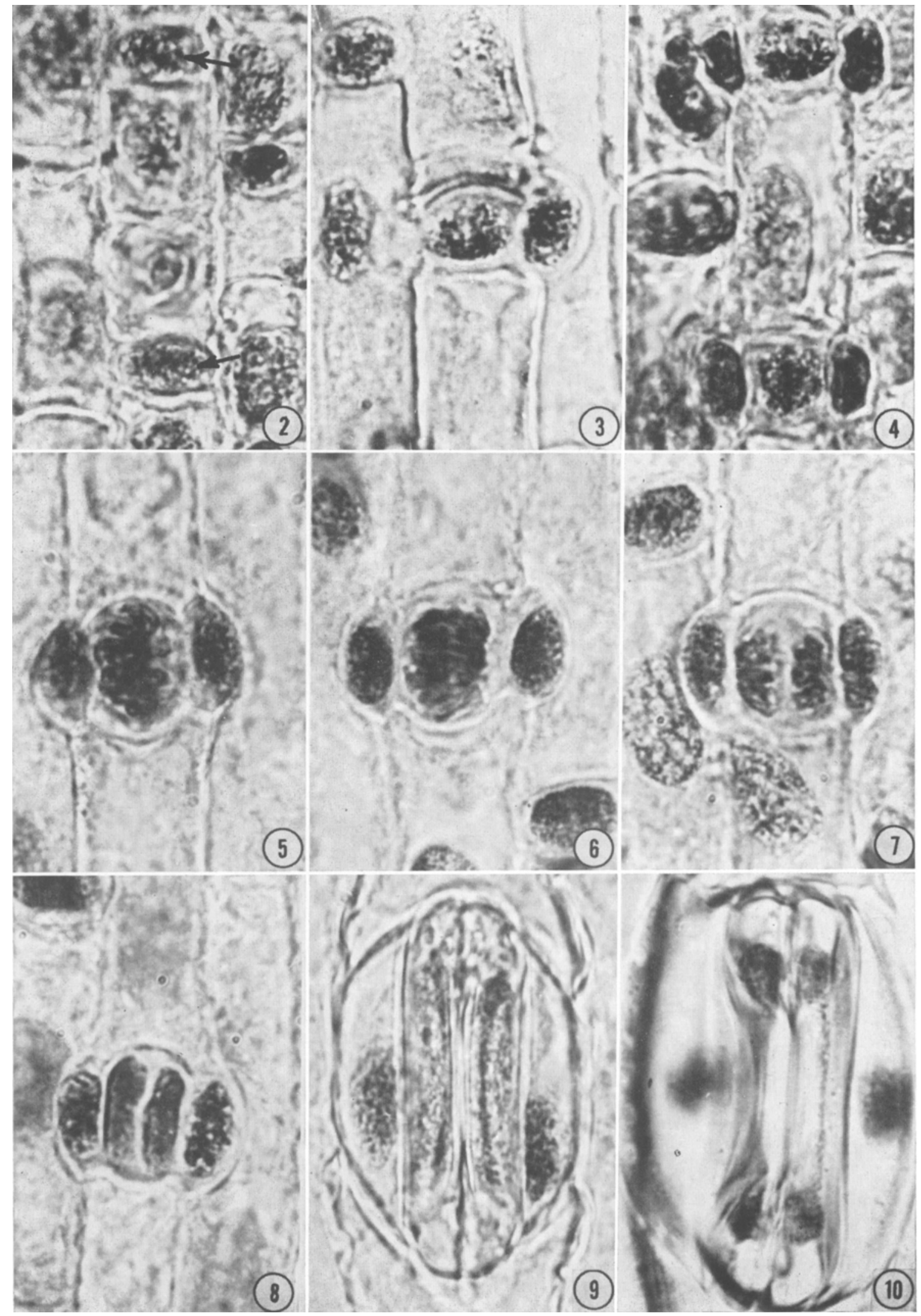


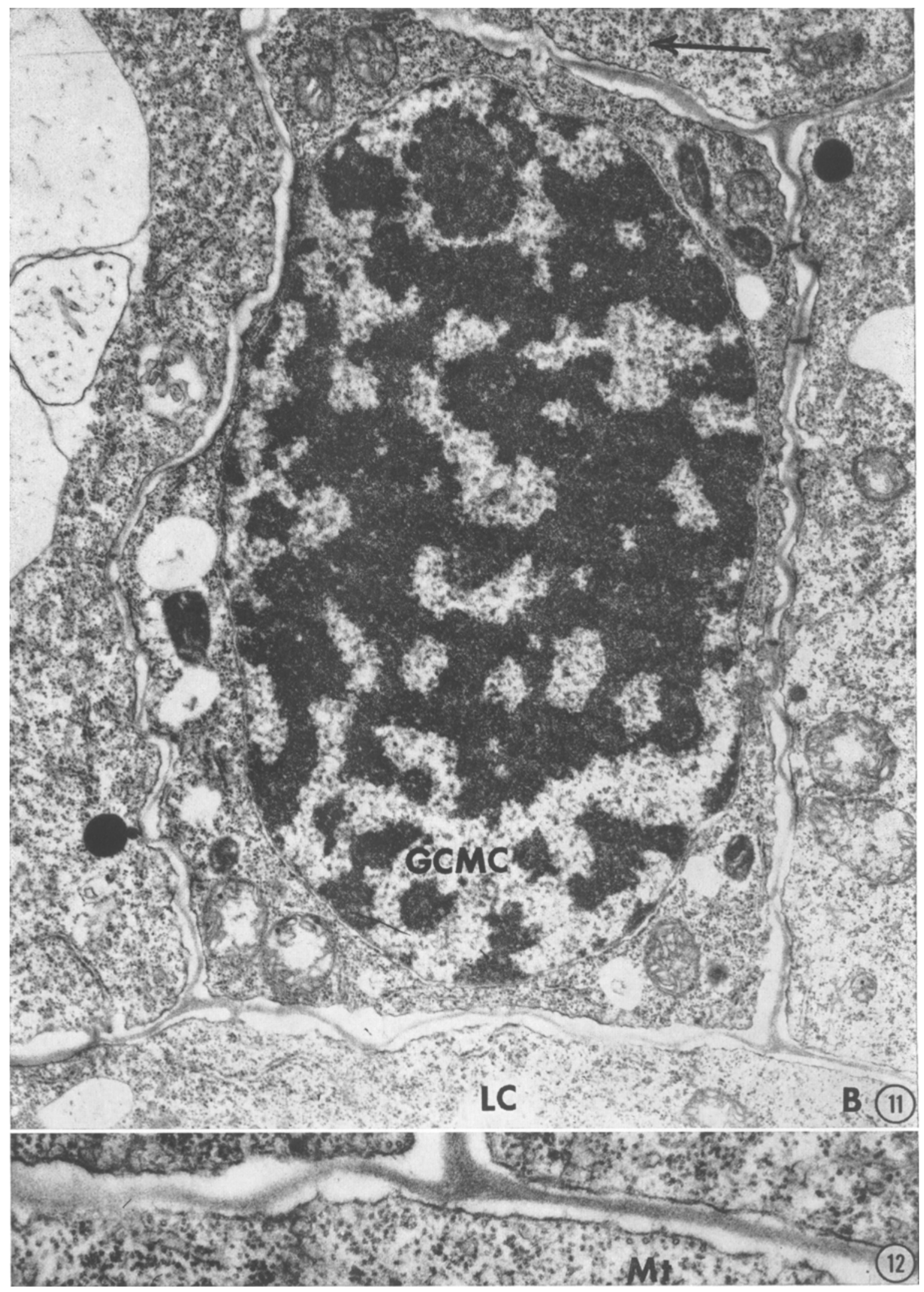




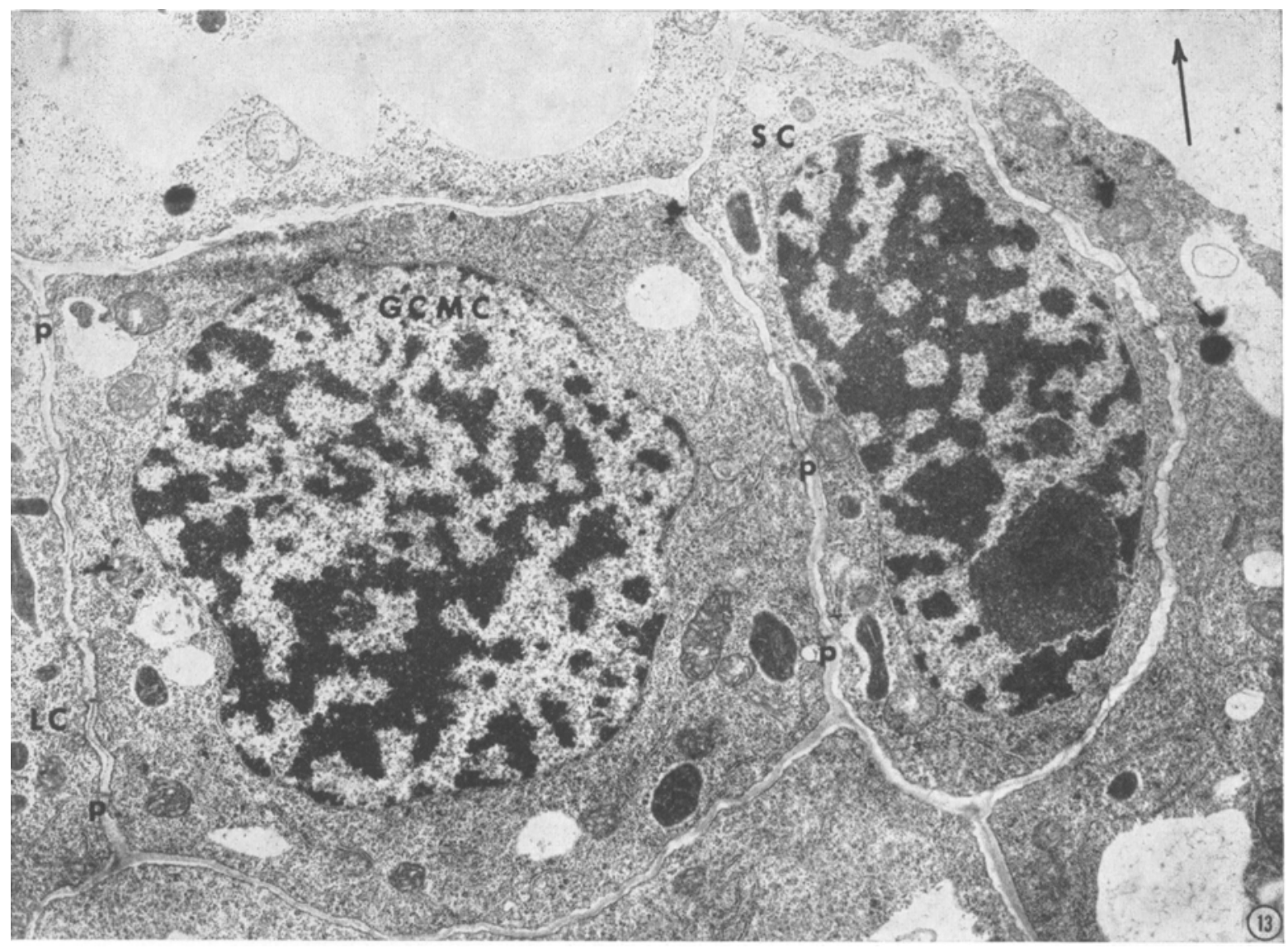

Fig. 13. A guard cell mother cell (GCMC) with associated subsidiary cell (SC), the doublet stage in stomata development. Plasmodesmata ( $p$ ) are evident between these two cells and between the subsidiary cell and the adjacent long cell (LC). Arrow indicates the long axis of the internode. $\times 10,000$.

The doublet stage is denoted by a single subsidiary cell and the associated GCMC (cf. Fig. $3,13)$. Figure 14 indicates an early stage in doublet formation where the cell that will become the first subsidiary is in late telophase stage of cell division with the cell plate developing centrifugally toward the parent cell wall.

The triplet stage (GCMC plus two subsidiary cells) is illustrated in Fig. 4, 15. The final division that leads to formation of the full complement of cells of the stomatal apparatus is a longitudinal division of the GCMC. It occurs only after both subsidiary cells have been cut off.

We shall designate the stage following this longitudinal division of the GCMC as the quartet stage of stoma development (cf. Fig. 8, 16, 17). Figure 17 shows the quartet after some differentiation has occurred in these cells, but before they have become greatly altered in form. Initially, these four cells, just after longitudinal division of the GCMC, appear very similar with respect to the kinds of organelles present and because of their lack of vacuolation (Fig. 16); however, at the slightly later stage illustrated in Fig. 17, vacuolation has been initiated first in the subsidiaries, and the proplastids of the guard cells have begun to accumulate starch grains. These are the first stages of differentiation of guard and subsidiary cells that we have been able to detect at the ultrastructural level in the quartet.

Cytoplasmic continuities in the developing stomatal apparatus-As previously reported by Brown and Johnson (1962), Miroslavov (1966), and Pickett-Heaps (1967a), a distinct pore occurs

Fig. 11, 12.-Fig. 11. View of guard cell mother cell (GCMC) just prior to formation of subsidiary cells. The first indication that this cell will form a stoma is the appearance of a band (B) of microtubules in the long cell (LC) lying adjacent to this short cell. Arrow indicates long axis of internode. $\times 20,000$.-Fig. 12. Enlarged view of region $B$ in Fig. 11 to illustrate the preprophase microtubules $(\mathrm{Mt}) . \times 42,500$. 


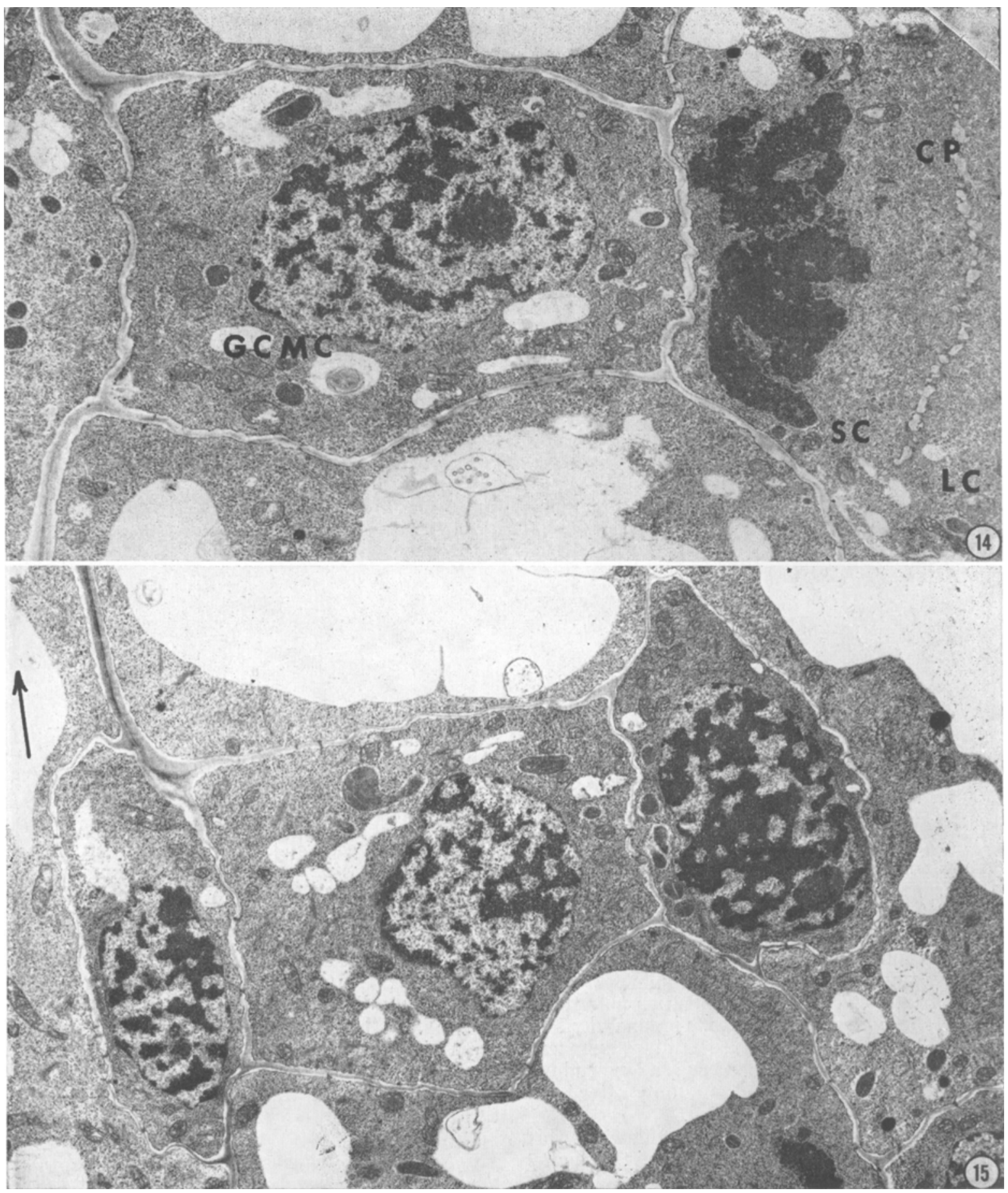

Fig. 14, 15.-Fig. 14. Telophase in a long cell (LC) that cuts off a subsidiary cell (SC) adjacent to the guard cell mother cell (GCMC). A centrifugally developing cell plate (CP) can be seen between SC and LC. The products of such a division are shown in Fig. 15. $\times 6,800$ - - Fig. 15. Triplet stage, consisting of a guard cell mother cell flanked by two subsidiary cells. The latter originate from the long cells on each side of the GCMC file. The division of the long cell below the GCMC is one which will give rise to a subsidiary cell. Arrow indicates long axis of the internode. $\times 6,800$. 


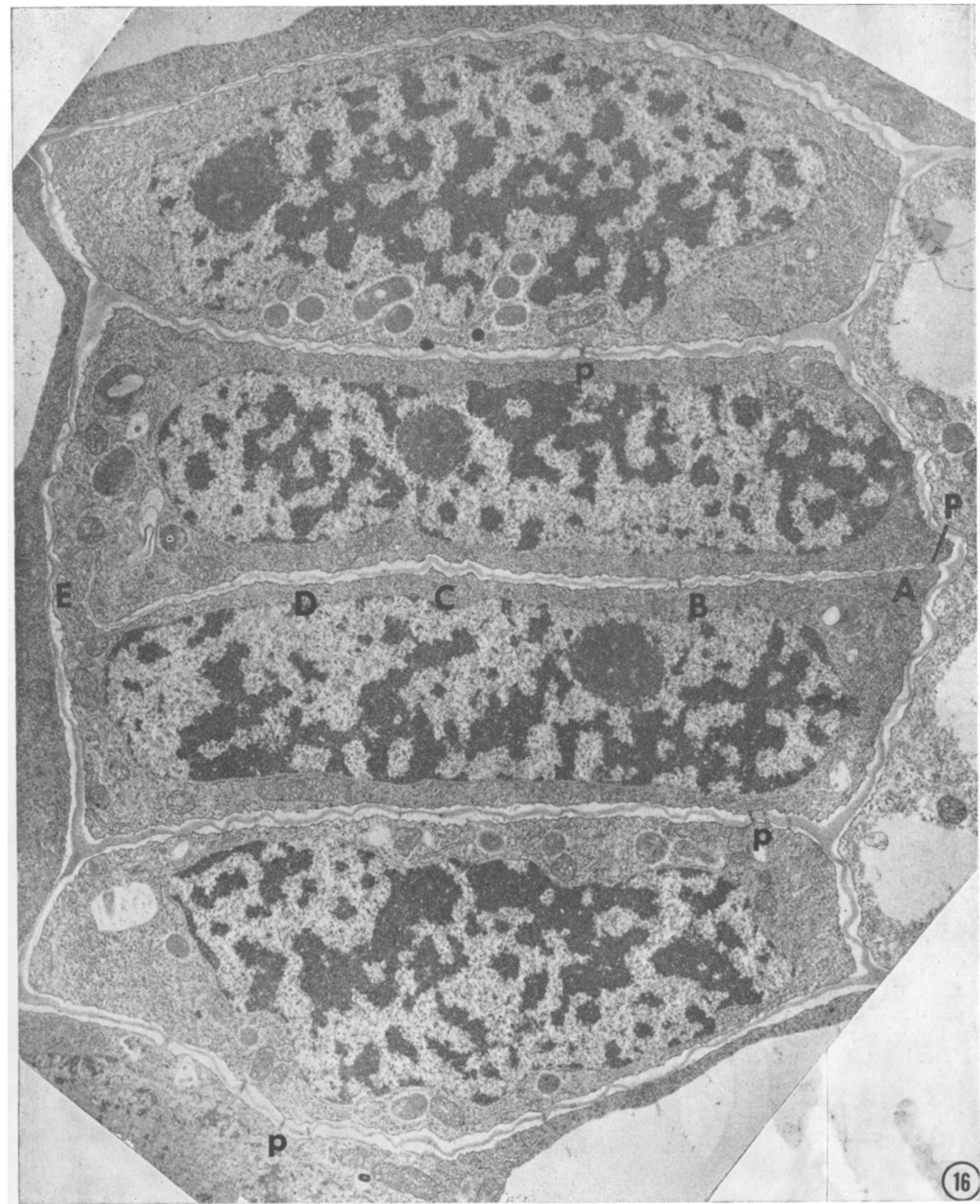

Fig. 16. Young stoma showing plasmodesmata $(\mathrm{p})$ between subsidiary cells and guard cells, and subsidiary cells and other epidermal cells. Also shown is a pore $(\mathrm{P})$ between the guard cells. Portions of wall labeled A, B, C, D, and E are enlarged in Fig. 18-20 to show microtubules adjacent to the wall. $\times 12,000$. 


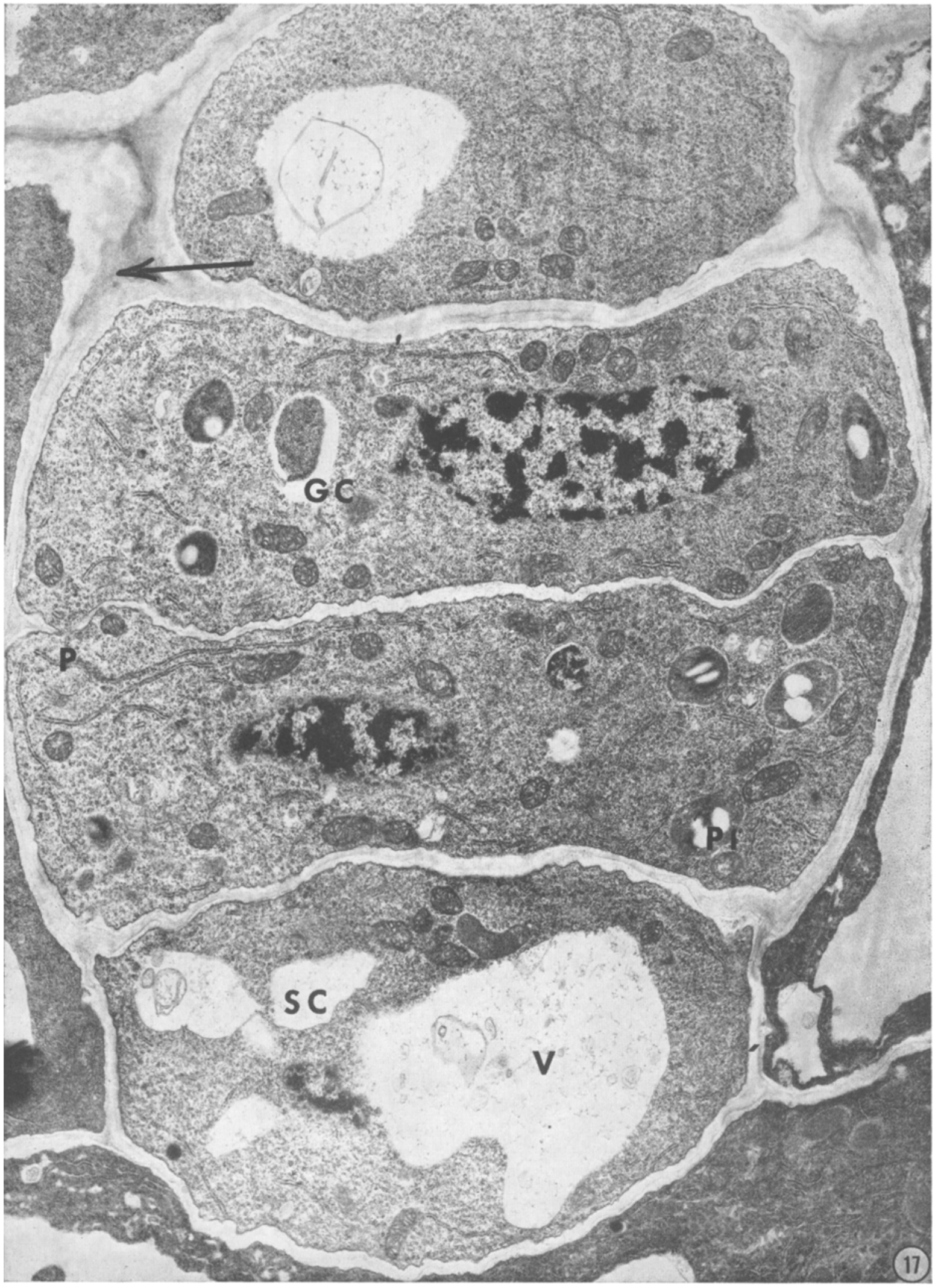


between the two guard cells near the ends of each of these cells in the grass stomata which have been examined. We also find such pores in Avena stomata (Fig. 16, 17). They are present from the time that guard cells in the quartet are first formed (Fig. 16). This suggests that the pores may result from the incomplete development of the wall formed after longitudinal division of the GCMC. In our material the mean diameter of these pores varied from between 0.15 and $0.25 \mu$ in mature stomata

Plasmodesmata can be found in the singlet (Fig. 11), doublet (Fig. 13, 14), triplet (Fig. 15), and early quartet (Fig. 16) stages of stoma development. From these illustrations, it is clear that there is cytoplasmic continuity via plasmodesmata in all cells of the developing stomatal apparatus and between the subsidiary cells and the adjacent long epidermal cells. The one shown in Fig. 18 has a diameter of $\sim 300 \mathrm{~A}$.

Wall thickening around the developing aperturePrior to aperture formation in young quartets, we have found a locus of microtubules just inside the plasmalemma along the center portion of the wall which is common to the two guard cells (Fig. 18). This locus is parallel to the wall and occurs at a site where the aperture will form and where localized wall thickening takes place later. On either side of this locus the microtubules are less concentrated (cf. Fig. 18-20). These microtubules lie parallel to the wall. Generally they are oriented perpendicular to the surface of the internode (Fig. 18-20), but occasionally they lie parallel to this surface.

After the appearance of these microtubules, the wall at this locus begins to thicken (Fig. 21, 22). Closely following early stages of wall thickening, an aperture appears (Fig. 23). As with the microtubules concentrated near the center portion of the common wall, the wall thickening is also very localized and appears to take place in precisely the same locus where the microtubules were concentrated (cf. Fig. 18, 21). This would be expected in light of similar observations made for secondary wall thickenings that develop in tracheids and vessel elements (Albersheim, 1965; Cronshaw, 1965). After considerable wall thickening has taken place (Fig. 24, 25), we find microtubules associated with the thickening portion of the wall, but at this stage they appear to be oriented in various planes running from the cytoplasm into the plasmalemma. The majority of these microtubules appear to be running in planes approximately perpendicular to the radial axis of the wall. The wall at this stage appears fairly homogeneous in our preparations. This wall around the aperture ultimately develops into an extremely thick pad (Fig. 26). Here, it is nearly twenty times thicker than the wall portions above and below this thickened region. Distinct lamellae can be seen throughout the pad-like thickening.

Plastid development in the stomatal apparatusFrom singlet to triplet stages in stoma development, we find that the GCMC and the subsidiary cells possess prominent proplastids (Fig. 11, 13-15), which have weakly developed internal lamellae and no apparent starch grains in them. In young quartets the proplastids may be seen in the subsidiary cells (Fig. 16), but in the guard cells small starch grains begin to appear in the plastids. Later, in the guard cells the plastids develop prominent starch grains (several per plastid) and an internal lamellar system which is not much more extensive than that seen in the proplastids (Fig. 22, 24, 27). In the most mature guard cells observed, some poorly developed grana stacks could be seen in the plastids (Fig. 27). From these observations it would appear (1) that the proplastids in the subsidiary cells do not accumulate starch and (2) that the proplastids in the guard cells, after early quartet stage, begin to develop into amyloplasts, and that these plastids have a weakly developed internal membrane system with some tendency to form grana stacks.

Late stages in differentiation of guard and subsidiary cells-As the stomatal apparatus matures the subsidiary cells become hemispherical (cf. Fig. 23, 26). They have ovoid nuclei, contain a large central vacuole and several smaller peripheral ones, and have no apparent starch-storing plastids. In contrast, the guard cells are rodshaped with the cytoplasm confined to a dumbbell-shaped volume because of the wall thickenings (Fig. 26). The cytoplasm contains starchstoring plastids and numerous small vacuoles in the bulbous ends (Fig. 26, 27), as also reported by Miroslavov (1966) for Secale stomata. The guard cell nuclei become greatly elongated and very narrow in their mid-regions because of the pad-like wall thickening around the stomatal aperture. Wall thickening also takes place at other sites in the stomatal apparatus. Such thickened areas can be seen in Fig. 26 along the outer walls of the guard cells near their ends and along the outer walls of the two subsidiary cells.

Discussion-Development of the stomatal com-

Fig. 17. Quartet stage. The guard cells (GC) have conspicuous starch-storing plastids (PI), small vacuoles, and a pore (P) at the end of the wall that is common to the two cells. The subsidiary cells (SC), in contrast, have conspicuous vacuoles (V) and lack starch-storing plastids. Arrow indicates the long axis of internode. $\times 12,000$. 


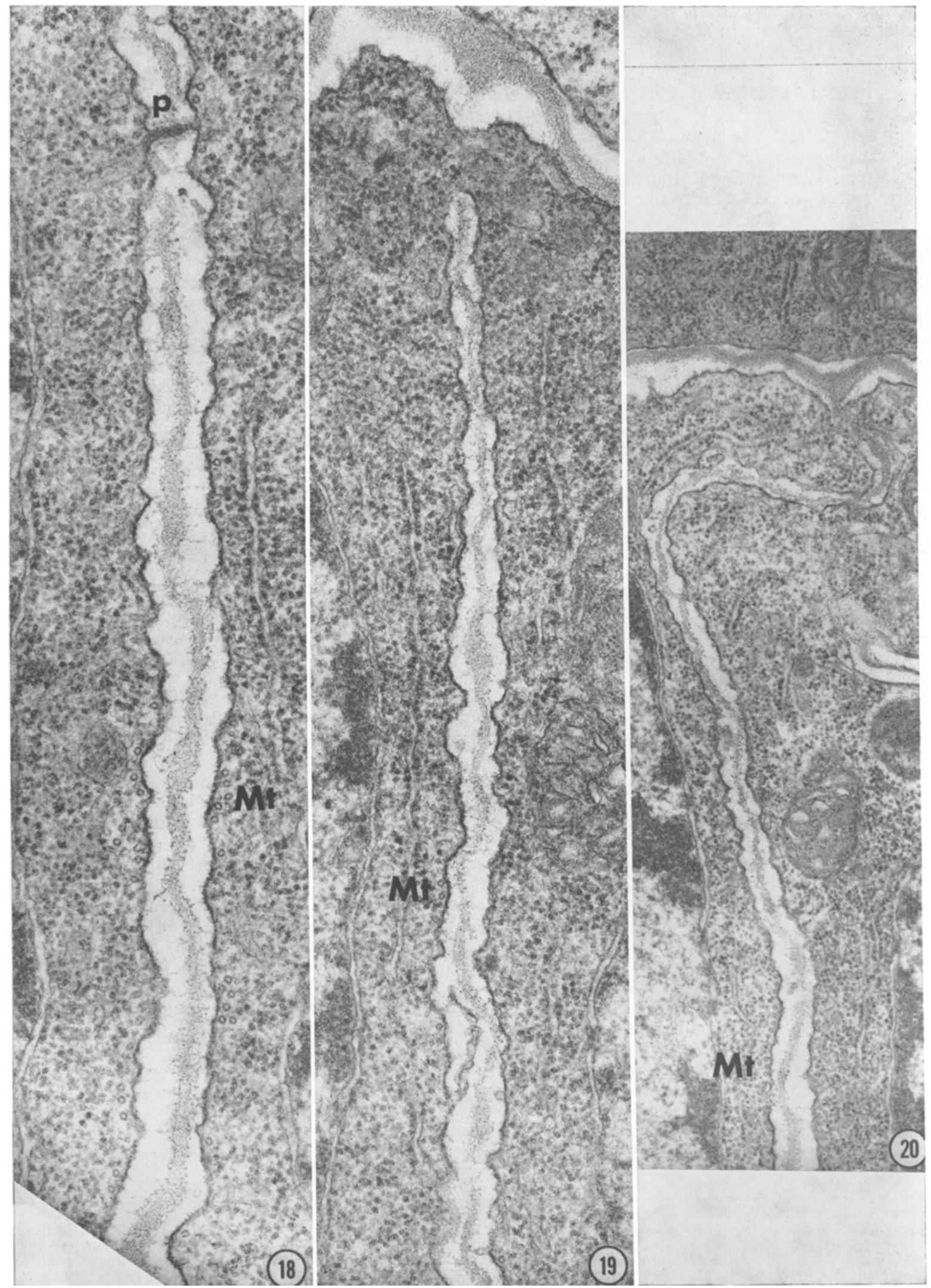




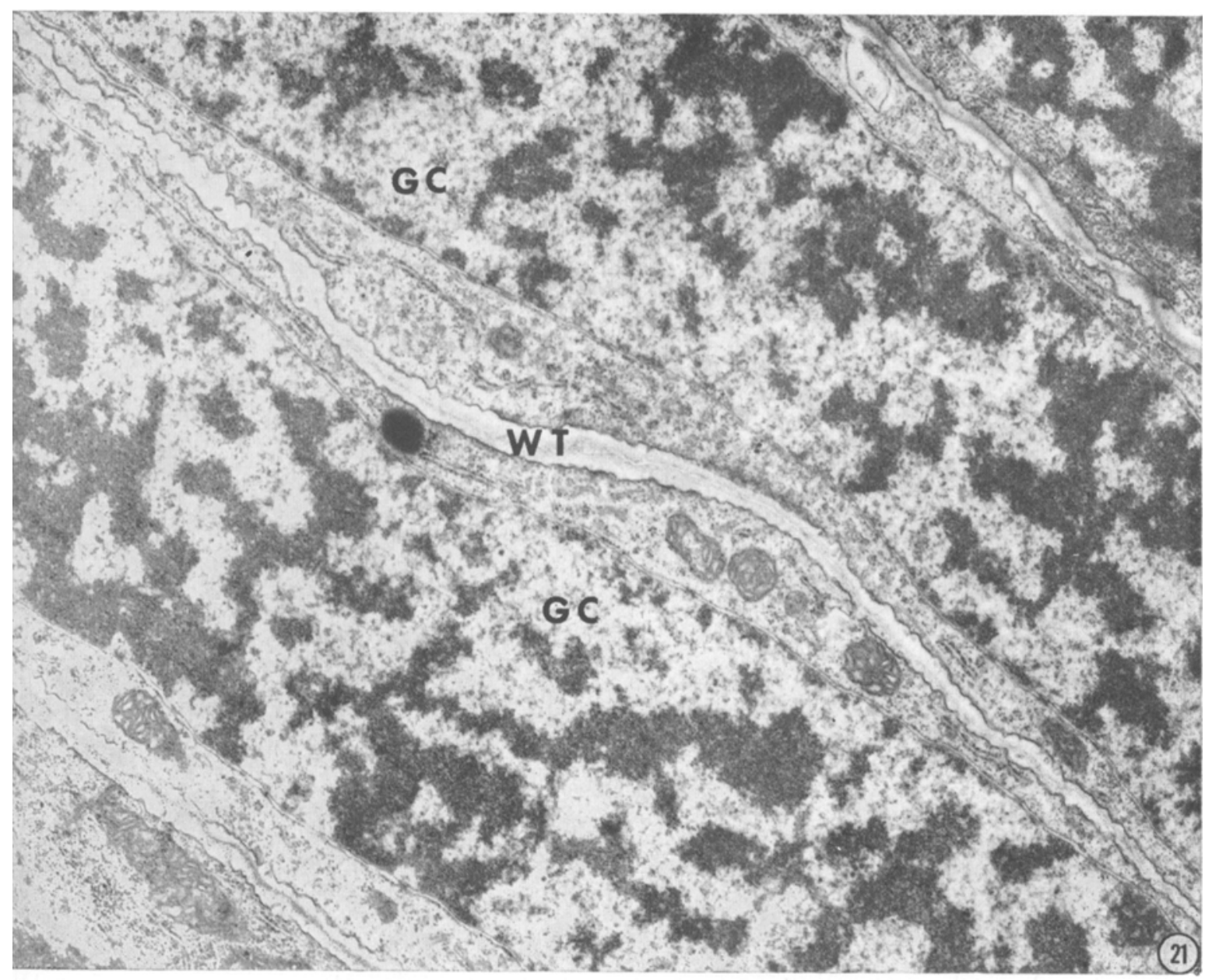

Fig. 21. Wall between two guard cells (GC), showing locus where the wall begins to thicken (WT). This is where the aperture will form. $\times 16,000$.

plex in grasses -The first event detected at the ultrastructural level which indicates that a particular short cell will differentiate into a stoma and not another type of idioblast is nuclear migration and the appearance of preprophase bands of microtubules in long epidermal cells just prior to subsidiary cell formation. Such microtubule bands were first demonstrated in the formation of stomatal complexes by PickettHeaps and Northcote (1966). Burgess and Northcote (1967) suggested that these bands of microtubules may function to orient the spindle in these long cells and thus to determine the orientation of the cell plate which cuts off a subsidiary cell. The actual signal which causes nuclear migration in the long cell is not known.

It is possible that some hormonal messenger derived from the short cell could act as an "effector" in inducing nuclear migration and the appearance of the microtubule bands (PickettHeaps and Northcote, 1966). We have found that exogenously supplied IAA and $\mathrm{GA}_{3}$ (at physiological levels) have a profound effect on the way in which long epidermal cells just above the intercalary meristem expand and on the plane of cell division in the GCMC in isolated Avena stem segments (Kaufman et al., 1969). Conceivably, these or other hormones could also

Fig. 18-20.-Fig. 18. View of center portion of wall common to the two guard cells (B to C in Fig. 16), showing a locus of microtubules $(\mathrm{Mt})$ at the position where the aperture will form, and a plasmodesm (p) ca. $300 \mathrm{~A}$ in diam. $\times 69,000$. -Fig. 19. View of end of wall common to the two guard cells (A to B in Fig. 16), showing fewer microtubules $(\mathrm{Mt})$ than at locus shown in Fig. 18. $\times 50,000$. - Fig. 20. View of other end of wall common to the two guard cells (D to E in Fig. 16), showing fewer microtubules (Mt) than at locus shown in Fig. 18. $\times 35,000$. 

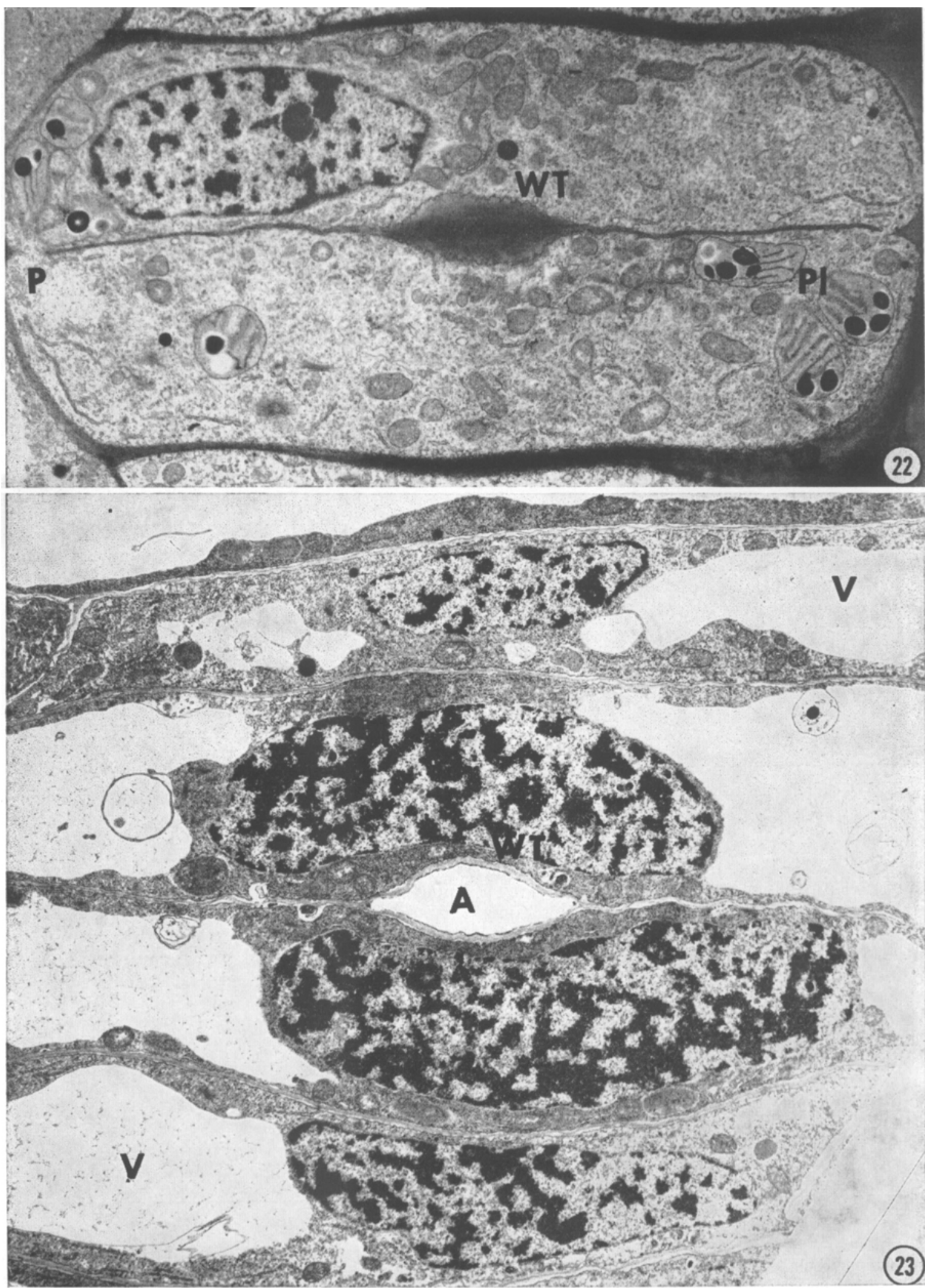


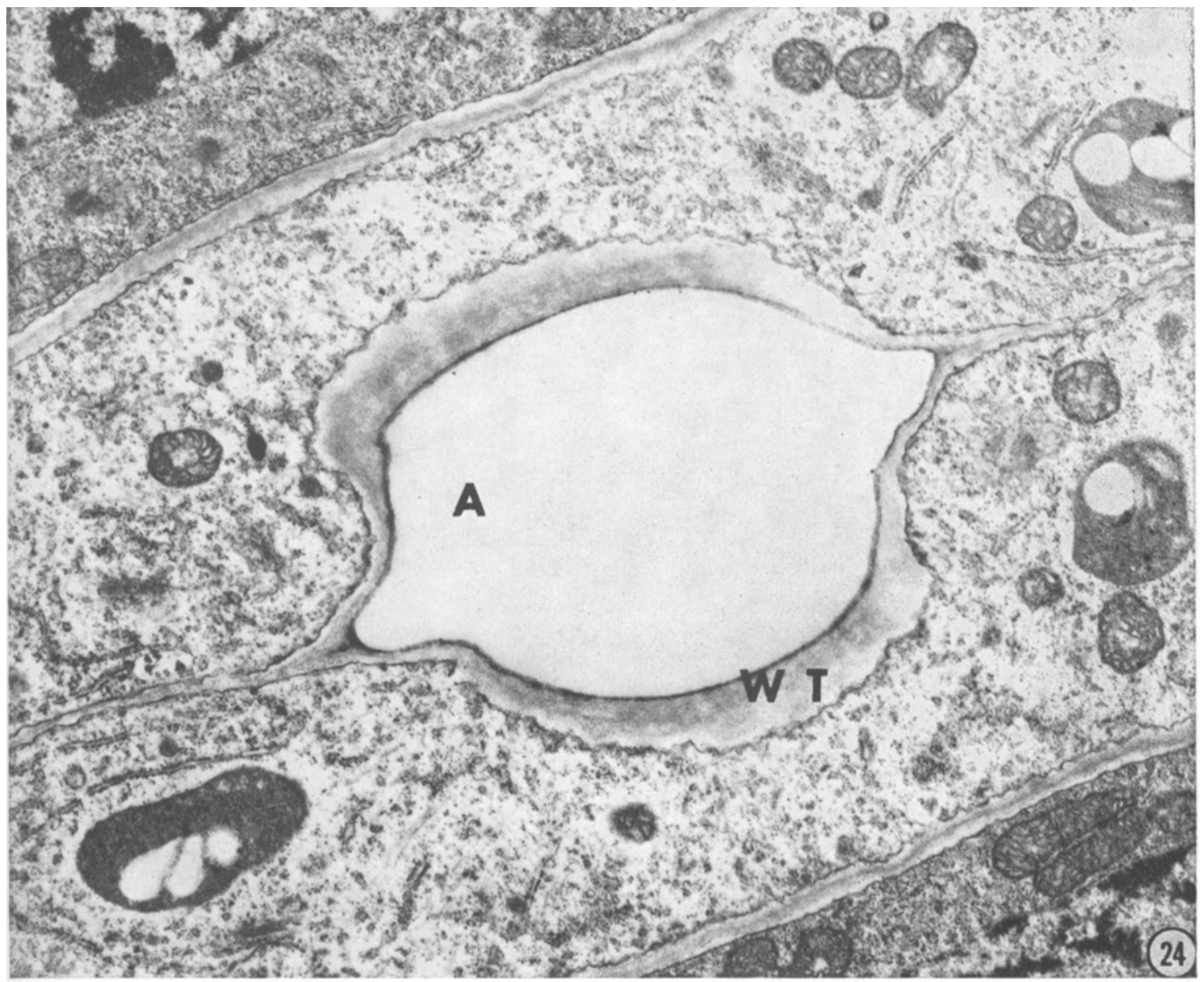

Fig. 24. Illustration of aperture (A) and associate1 thickened wall (WT) between two guard cells at intermediate quartet stage of stoma development. $\times 15,700$.

play a role in nuclear migration and in the formation of microtubule bands. Since IAA $\left(10^{-5}\right.$ to $10^{-7} \mathrm{M}$ ) in particular has a marked influence on plane of cell division in the young stomatal complexes, it would be extremely interesting to determine the effects of this hormone on the nuclear migration and on the appearance of microtubule bands in long epidermal cells which take part in stoma development.

After the appearance of the microtubule bands, two subsidiary cells are cut off, sequentially or concurrently, leading to doublet and triplet stages in stoma development (Fig. 13-15). Our ultrastructural studies show that the GCMC and two subsidiary cells are morphologically similar with respect to vacuolation patterns and the types of organelles present in these cells. Both types of cells at the triplet stage contain proplastids with no apparent starch grains in them. It is important to emphasize this similarity, because later in the quartet stage these organelles follow divergent pathways of development in the two types of cells.

The next stage in stoma development is a longitudinal division of the GCMC, as illustrated in Fig. 5-8 for Avena, and also illustrated by Porterfield (1937), Flint and Moreland (1946), and Pickett-Heaps and Northcote (1966) for other grass stomata. This third division leads to formation of two young guard cells, and thus a quartet of cells now constitutes the stomatal apparatus. One of the significant features at this

Fig. 22, 23.-Fig. 22. View of pair of guard cells showing later stage of wall thickening (WT) and early stage of lysis of the middle lamella at site where the aperture will appear. Pores (P) between guard cells and plastids (PL) in these cells can be seen. $\times 7,500$.- Fig. 23. View of quartet at intermediate stage of stoma development illustrating aperture (A) and wall thickening (WT) around the aperture. Large vacuoles (V) occur in both subsidiary and guard cells. $\times 7,500$ : 

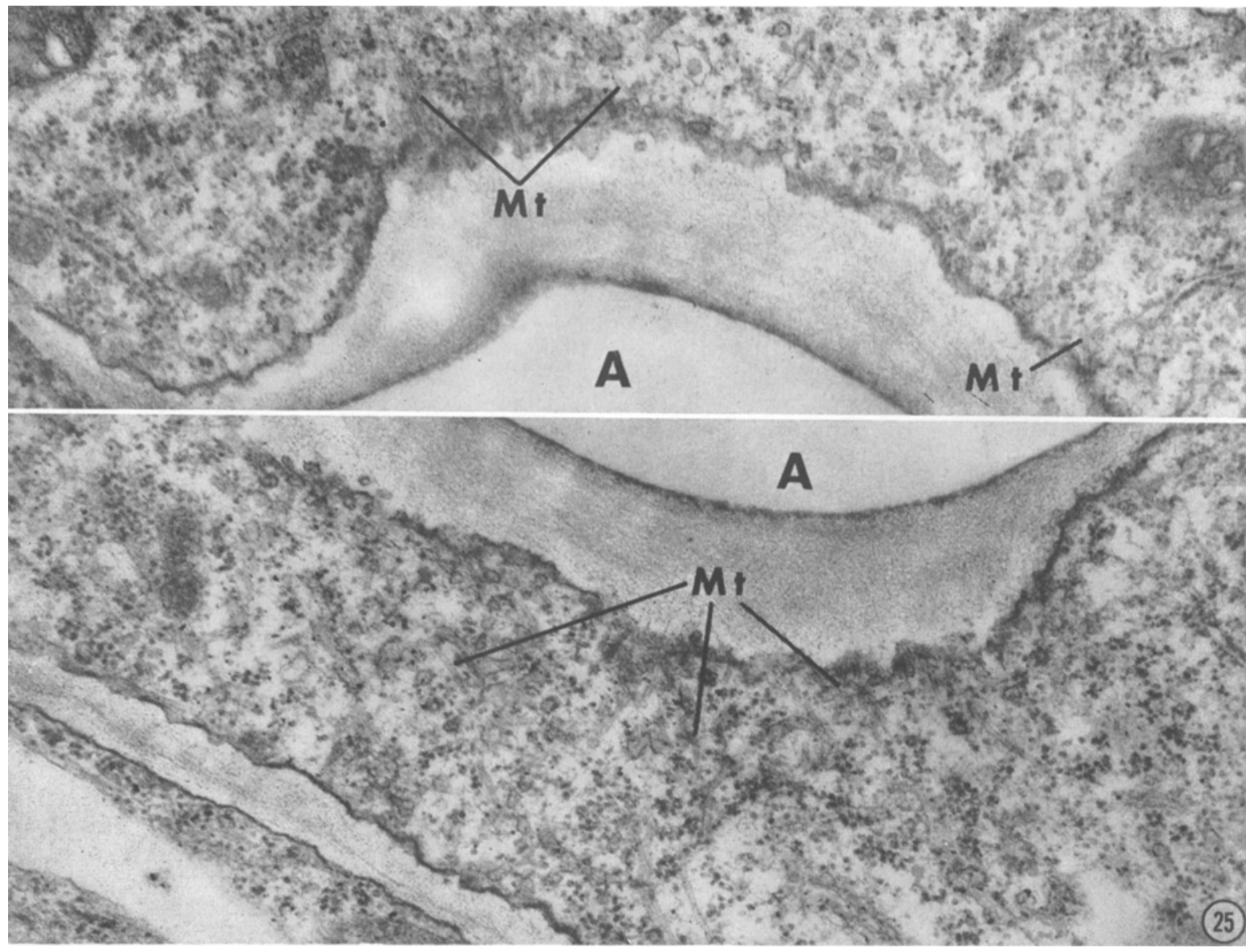

Fig. 25. Portions of the guard cells adjacent to the aperture (A) surrounded by a thickened wall. Leading from the cytoplasm into the periphery of the wall are large numbers of microtubules (Mt) oriented in various planes. Many of the microtubules are undulate. $\times 37,500$.

stage in stoma development is the occurrence of one or more pores near the ends of the guard cells in the common wall between these two cells. Such pores are first described in ultrastructural studies by Brown and Johnson (1962) in mature grass stomata. They have since been demonstrated in stomata of other grasses by Miroslavov (1966) and Pickett-Heaps (1967a). We have also found them in Avena stomata. The important point is that we have found these pores at all stages of development of the stomatal complex from very early quartet stage (Fig. 16) through intermediate and late quartet stages (Fig. 17, $22,27)$. One of the questions raised by PickettHeaps and Northcote (1966) is whether these pores arise as a result of localized lysis of the cell wall, or if they are formed as a result of incomplete wall development during longitudinal division of the GCMC. Our studies support the second interpretation.

In addition to these pores, we also find plasmodesmata between guard and subsidiary cells in Avena stomata up through early quartet stage of development (Fig. 13-16). Brown and Johnson
(1962) found no plasmodesmata between guard and subsidiary cells of mature stomata, and Miroslavov (1966) makes no mention of plasmodesmata. Sievers (1959) has reported the occurrence of plasmodesmata between guard and subsidiary cells. The main point here is that during development of the stomatal apparatus, in Avena and probably in other grasses, there is cytoplasmic continuity as revealed by (1) the presence of plasmodesmata between all cells of young stomata, as well as between these cells and adjacent epidermal cells, and (2) the presence of pores between the guard cells from the time they are first formed.

During stoma development, in young quartets we have found a concentration of microtubules along the wall common to the two guard cells at the locus where the stoma will form later and where localized wall thickening takes place (Fig. $16,18)$. Before wall thickening these microtubules are oriented primarily parallel to the radial plane of the wall. After wall thickening and aperture formation begin, microtubules are also seen in the same locus, but they now are oriented 


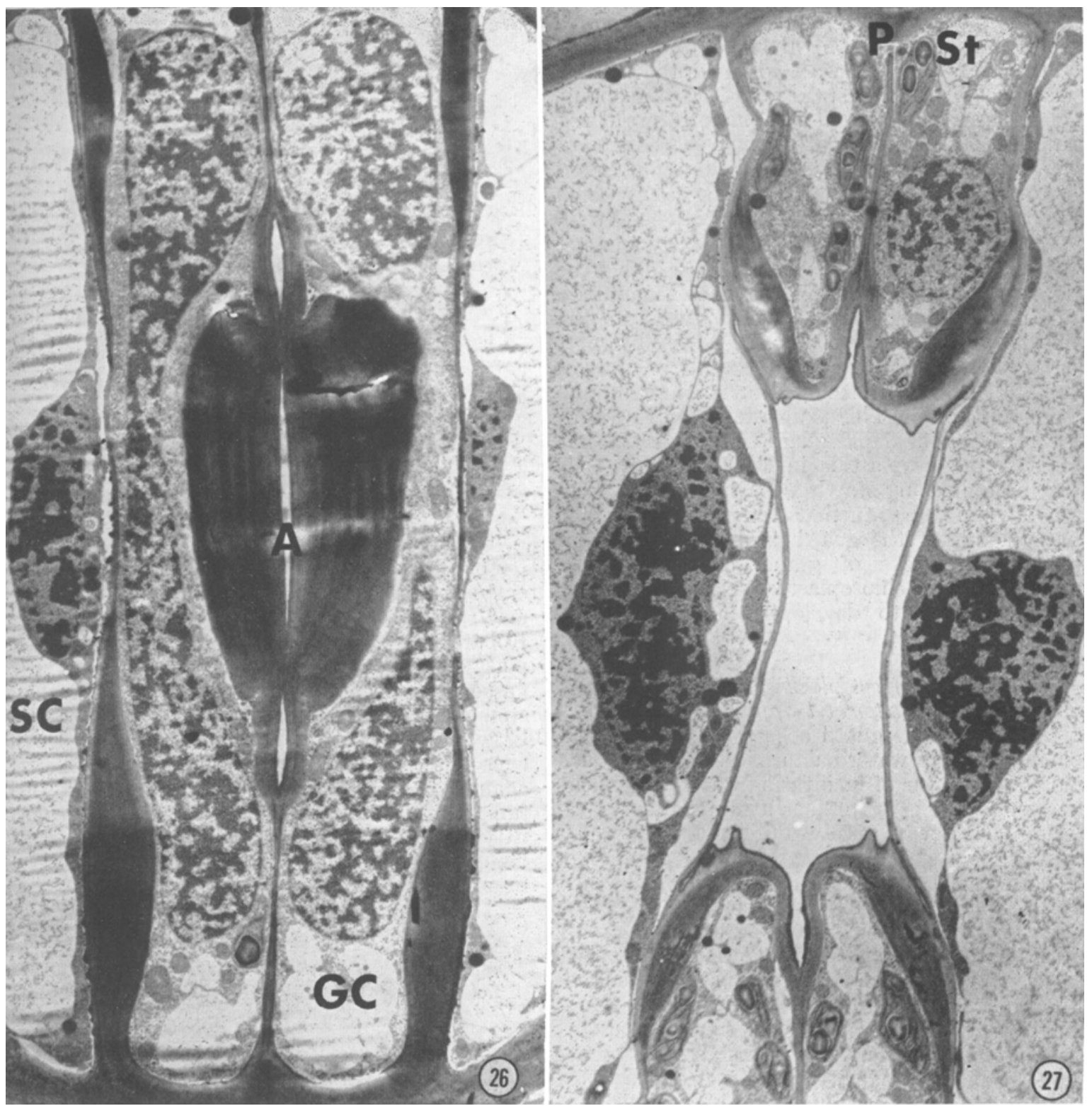

Fig. 26, 27.-Fig. 26. Mature stomatal apparatus in paradermal view approximately in the median plane of the stoma showing subsidiary cells partly (SC), guard cells (GC), and the aperture (A). $\times 6,700$.-Fig. 27. Paradermal view of the same stoma shown in Fig. 26 sectioned closer to the cortex of the internode. Shown are the pore (P) and the starch (St) in the guard cells. $\times 6,300$.

primarily perpendicular to the radial plane of the wall (Fig. 24, 25). Green and King (1966) found that in elongating Nitella cells the orientation of the microtubules was essentially the same as that of the cellulose microfibrils, and they suggested that these microtubules could be involved in orienting cell-wall synthesis. From his studies on the effects of colchicine on xylem wall differentiation in wheat, Pickett-Heaps (1967b) visualizes the microtubules as playing a decisive role in control of wall thickening and development in these cells. Mühlethaler (1967) and others have proposed that microtubules are involved in channeling polysaccharide precursors into the cell wall.

Since in Avena stomata development there appears to be a change in orientation of the microtubules from the radial plane to a plane more or less perpendicular to the cell wall, it is difficult to ascribe a function to these microtubules. It is inviting to suggest that in the early quartet stage of stoma development, when the guard 
cells are elongating rapidly, the parallel oriented microtubules could be involved in orienting synthesis in the cell wall common to the two guard cells in early stages of wall thickening. Later, after the guard cells have stopped expanding, and cell wall thickening is well underway, the more or less perpendicularly oriented microtubules could serve as tracks along which polysaccharide precursors move into the cell wall.

Lastly, in connection with the early quartet stage of stomata development, we observe that the proplastids in the guard cells begin to accumulate starch grains, whereas the proplastids in the subsidiary cells do not (Fig. 17). We interpret these plastids in the guard cells to be amyloplasts with weakly developed internal membrane systems (Fig. 27). This is also reported by Miroslavov (1966) for Secale guard-cell plastids. What prevents the proplastids in the subsidiary cells from accumulating starch is an interesting question which deserves further study. Also, why is it that plastids of the guard cells do not develop well-defined stacks of grana, as for example in the spinach chloroplast. (Weier, 1961), but instead, appear to develop into "quasiamyloplasts"?

Possible roles of cytoplasmic connections in the functioning of the stomatal apparatus-The pores at the ends of the guard cells most likely play a role in control of water balance in the stoma. This role could be one of facilitating water movement between guard cells in their attainment of equilibrium after changes in osmotic potential or hydrostatic pressure in the guard and subsidiary cells. In such a system the guard cells would thus act as a unit with respect to changes in water balance. The puncturing experiments of Heath (1938) with Tradescantia stomata demonstrated that the stoma closes when one guard cell, or any other cell of the stomatal apparatus, is punctured. Whether pores are present in these stomata is not known. Comparable experiments should be attempted with guard cells of grass stomata where pores are known to be present. Obviously, the pores could also serve as avenues of movement of cellular organelles from one guard cell to the other. This idea is supported by the fact that organelles such as endoplasmic reticulum, ribosomes, and plastids have been observed in the pore itself (Miroslavov, 1966; Fig. 17). Direct proof of movement of such organelles has yet to be demonstrated, however.

At first sight the plasmodesmata would appear to offer a path of viscous flow between young guard and subsidiary cells and, therefore, decrease any pressure differential between these two cells. However, a calculation of the volume flux via the plasmodesmata, with the meager data at hand, gives a value of about $10 \%$ of the calculated osmotic flux between guard and subsidiary cells.
We assume that:

$$
\begin{aligned}
10 \times 30 \mu & =\begin{array}{l}
\text { surface between guard and sub- } \\
\text { sidiary cells. }
\end{array} \\
2 \mathrm{bars} & =\text { pressure differential } \\
\frac{10^{-5} \mathrm{~cm}}{\mathrm{sec} \cdot \mathrm{bar}} & =\text { osmotic permeability }
\end{aligned}
$$

If viscous flux $=\mathrm{k} \cdot \Delta \cdot \mu$

where $\mathrm{k}=$ osmotic permeability

$\triangle=$ pressure differential

$\mu=$ surface between guard and subsidiary cells

$$
\begin{aligned}
\text { Then viscous flux }= & \frac{10^{-5} \mathrm{~cm}}{\mathrm{sec} \cdot \mathrm{bar}} \cdot 2 \mathrm{bars} . \\
& \frac{10 \mu \times 30 \mu}{10^{8} \mu^{2} / \mathrm{cm}^{2}} \\
& \cong 6 \times 10^{-11} \mathrm{~cm}^{3} / \mathrm{sec}
\end{aligned}
$$

For protoplasm, the viscous flux $=\sim 10^{-12}$ $\mathrm{cm}^{3} / \mathrm{sec}$, and for ribosomes, it is $10^{-3}$ to $10^{-4}$ $\mathrm{cm}^{3} / \mathrm{sec}$. If tubules (termed desmotubules by Robards) occupy an appreciable fraction of the plasmodesm (Robards, 1968), the viscous flux value for plasmodesmata would be less. Since stomatal regulation requires a pressure differential between the guard and subsidiary cells, one would expect that plasmodesmata would be selected against in evolution. If, on the other hand, they function in additional ways to viscous "leaks," they would be retained. Perhaps they serve here, and in other pairs of cells, as a route of information transfer.

\section{LITERATURE CITED}

Albersheim, P. 1965. The substructure and function of the cell wall, p. 151-186. In J. Bonner and J. E. Varner [ed.], Plant biochemistry. Academic Press, New York.

Ariyanayagam, D. V., and G. L. Stebbins. 1962. Developmental studies of cell differentiation in the epidermis of monocotyledons. III. Interaction of environmental and genetic factors on stomatal differentiation in three genotypes of barley. Dev. Biol 4: 117-133.

Bonnetr, O. T. 1961. The oat plant; its histology and development. Univ. 11l. Agr. Exp. Sta. Bull. 672: 1112.

Brown, W. V., AND S. C. Johnson. 1962. The fine structure of the grass guard cell. Amer. J. Bot. 49: $110-115$.

Burgess, J., AND D. H. NonthCote. 1967. A function of the preprophase band of microtubules in Phleum pratense. Planta 75: $319-326$.

Camprell, D. H. 1881. On the development of the stomata of Tradescantia and Indian corn. Amer. Natur. 15: 761-766.

Cronshaw, J. 1965. The organization of cytoplasmic components during the phase of cell wall thickening in differentiating cambial derivatives of Acer rubrum. Can. J. Bot. 43: 1401-1407. 
Fuint, L. H., and C. F. Morniland. 1946. A study of the stomata in sugarcane. Amer. J. Bot. 33: 80-82.

Green, P. B., AND A. King. 1966. A mechanism for the origin of specifically oriented textures in development with special reference to Nitella wall texture. Aust. J. Biol. Sci. 19: 421-437.

HeAtн, O. V. S. 1938. An experimental investigation of the mechanism of stomatal movement, with some preliminary observations upon the response of the guard cells to shock. New Phytol. 37: 385-395.

Karnovsky, M. J. 1965. A formaldehyde-glutaraldehyde fixative of high osmolality for use in electron microscopy. J. Cell Biol. 27: 137A.

Kaufman, P. B. 1959. Development of the shoot of Oryza sativa. II. Leaf histogenesis. Phytomorphology 9: 277-311.

- AND S. CAssell. 1963. Striking features in the development of internodal epidermis in the oat plant (Avena sativa). Mich. Bot. 2: 115-121.

- , L. B. Petering, and P. A. Adams. 1969. Regulation of growth and cellular differentiation in developing Avena internodes by gibberellic acid and indole-3-acetic acid. Amer. J. Bot. 56: 918-927.

KetellapPer, H. J. 1963. Stomatal physiology. Ann. Rev. Plant Physiol. 14: 249-270.

Mrroslavov, E. A. 1966. Electron microscopic studies of stomata of the leaf of rye Secale cereale L. [Transl. from Russian]. Bot. Zh. 51: 446-449.

Mollenhauer, H. H. 1964. Plastic embedding mixtures for use in electron microscopy. Stain Technol. 39: $111-114$.

Mühlethalen, K. 1967. Ultrastructure and formation of plant cell walls. Annu. Rev. Plant Physiol. 18: $1-24$.
Picketr-Heaps, J. D. 1967a. Further observations on the Golgi apparatus and its function in cells of the wheat seedling. J. Ultrastruct. Res. 18: 287-303.

- 1967b. The effects of colchicine on the ultrastructure of dividing plant cells, xylem wall differentiation and distribution of cytoplasmic microtubules. Dev. Biol. 15: 206-236.

- and D. H. Nonthcote. 1966. Cell division in the formation of the stomatal complex of the young leaves of wheat. J. Cell Sci. 1: 121-128.

Porterfield, W. M. 1937. Histogenesis in the bamboo with special reference to the epidermis. Torrey Bot. Club Bull. 64: 421-432.

Reynolds, E. S. 1963. The use of lead citrate at high $p \mathrm{H}$ as an electron-opaque stain in electron microscopy. J. Cell Biol. 17: 208-213.

RoBARDS, A. W. 1968. A new interpretation of plasmodesmatal ultrastructure. Planta 82: 200-210.

Setterfield, G. 1957. Fine structure of guard-cell walls in Avena coleoptile. Can. J. Bot. 35: 791-793.

Sievers, A. 1959. Untersuchungen über die Darstellbarkeit der Ektodesmen und ihre Beeinflussung durch physikalische Faktoren. Flora 147: 263-316.

Stebbins, G. L., and G. S. Khush. 1961. Variation in the organization of the stomatal complex in the leaf epidermis of monocotyledons and its bearing on their phylogeny. Amer. J. Bot. 48: 51-59.

- AND S. S. SHAH. 1960 . Developmental studies of cell differentiation in the epidermis of monocotyledons. II. Cytological features of stomatal development in the Gramineae. Dev. Biol. 2: 477-500.

Weier, T. E. 1961. The ultramicrostructure of starchfree chloroplasts of fully expanded leaves of Nicotiana rustica. Amer. J. Bot. 48: 615-630. 